November 1997 (revised September 1999)

\title{
A Model for the Federal Funds Rate Target*
}

\begin{abstract}
This paper is a statistical analysis of the manner in which the Federal Reserve determines the level of the Federal funds rate target, one of the most publicized and anticipated economic indicators in the financial world. The analysis presents two econometric challenges: (1) changes in the target are irregularly spaced in time; (2) the target is changed in discrete increments of 25 basis points. The contributions of this paper are: (1) to give a detailed account of the changing role of the target in the conduct of monetary policy; (2) to develop new econometric tools for analyzing time-series duration data; (3) to analyze empirically the determinants of the target. The paper introduces a new class of models termed autoregressive conditional hazard processes, which allow one to produce dynamic forecasts of the probability of a target change. Conditional on a target change, an ordered probit model produces predictions on the magnitude by which the Fed will raise or lower the Federal funds rate. By decomposing Federal funds rate innovations into target changes and nonchanges, we arrive at new estimates of the effects of a monetary policy "shock."

- JEL Classification: C22, C25, C41

- General Field: Time Series Econometrics
\end{abstract}

James D. Hamilton

Department of Economics, 0508

University of California, San Diego

9500 Gilman Dr.

La Jolla, CA 92093

e-mail: jhamilton@ucsd.edu

Oscar Jorda

Department of Economics

University of California, Davis

One Shields Avenue

Davis, CA 95616-8578

e-mail: ojorda@ucdavis.edu

*This paper is based on research supported by the NSF under Grant No. SBR-9707771. 


\section{Introduction}

This paper is a statistical analysis of the manner in which the Federal Reserve System (the Fed) determines the level of short-term interest rates in the U.S. In particular, we study when and how the Fed decides to change the level of the Federal funds rate target, one of the most publicized and anticipated indicators for financial markets all over the world. The target (for short) is an internal objective that is unilaterally set by the Chairman of the Federal Reserve System in compliance with the directives agreed upon at the Federal Open Market Committee (FOMC) meetings. The target is used by the Trading Desk of the Federal Reserve Bank of New York as a guide for the daily conduct of open market operations. We believe the target is of considerable economic interest precisely because it is not the outcome of the interaction of supply and demand of Federal funds and it is not subject to technical fluctuations or extraneous sources of noise. Rather, it is an operational indicator of how the direction of monetary policy determined by the FOMC is translated into practice.

Often a long period goes by before there is any change in the target. When the target is changed, it is usually in discrete increments of 25 basis points. Forecasting the target thus requires a dynamic model for limited dependent variables. There are not many tractable options for econometric analysis of such series. The dynamic probit specification (Eichengreen, Watson, and Grossman, 1985; Davutyan and Parke, 1995) has the drawback of requiring difficult numerical integrations. Monte Carlo Markov chain simulations (McCulloch and Rossi, 1994; Dueker, 1998) and importance-sampling simulation estimators (Lee, 1999) are promising alternative estimation strategies. The autoregressive conditional duration (ACD) model 
of Engle and Russell $(1997,1998)$ and Engle (1999) has the advantage over either of these approaches in providing a closed-form solution for the likelihood function and forecasts. It has the disadvantage, however, that it is awkward to update the forecast on the basis of information that has arrived since the most recent target change.

Engle and Russell's ACD specification poses the question, How much time is expected to pass before the next event (e.g., target change) occurs? Here we reframe the question as, How likely is it that the target will change tomorrow, given all that is known today? We describe this framework as the autoregressive conditional hazard $(\mathrm{ACH})$ model.

Our proposed $\mathrm{ACH}$ framework is introduced in Section 2. This class of time-series processes includes as a special case a discrete-time version of the ACD framework. Section 3 develops the formal connection between the $\mathrm{ACH}$ and $\mathrm{ACD}$ specification of the likelihood function. Our $\mathrm{ACH}$ specification has the advantage over the ACD model that it readily allows one to incorporate updated explanatory variables in addition to lagged target changes in order to form a forecast of whether the Fed is likely to change the target again soon.

Section 4 shows how this framework can be used to forecast the level of the Fed funds target, which requires predicting not only whether a change will occur but also the magnitude and direction of the change. We suggest that, conditional on a change in the target, one can use an ordered probit model to describe the size of the change.

Section 5 discusses the institutional background for the target, which motivates several details of the particular specification used in the empirical results presented in Section 6 . The forecasting performance of these ACH estimates is evaluated in Section 7. The dynamics 
of the Fed funds target described by our model are then used in a policy analysis exercise described in Section 8. Section 9 concludes.

\section{The Autoregressive Conditional Hazard Model}

The autoregressive conditional duration (ACD) model of Engle and Russell (1998) describes the average interval of time between events. Let $\tilde{u}_{i}$ denote the length of time between the $i$ th and the $(i+1)$ th time the Fed changed the target, and let $\tilde{\psi}_{i}$ denote the expectation of $\tilde{u}_{i}$ given past observations $\tilde{u}_{i-1}, \tilde{u}_{i-2}, \ldots$. The $\operatorname{ACD}(m, r)$ model posits that ${ }^{1}$

$$
\tilde{\psi}_{i}=\omega+\sum_{j=1}^{m} \alpha_{j} \tilde{u}_{i-j}+\sum_{j=1}^{r} \beta_{j} \tilde{\psi}_{i-j}
$$

Engle and Russell show that the resulting process for durations $\tilde{u}_{i}$, when indexed by the cumulative number of target changes $i$, admits an $\operatorname{ARMA}(\max \{m, r\}, r)$ representation with the $j$ th autoregressive coefficient given by $\alpha_{j}+\beta_{j}$. Thus stationarity requires $\sum_{j=1}^{m} \alpha_{j}+$ $\sum_{j=1}^{r} \beta_{j}<1$.

The basic premise of our approach is that observations on the process only occur at discrete points in time. Although one could use our method with daily data, little is lost by analyzing the funds rate target changes on a weekly frequency for the institutional reasons given in Section 5 below. Define $x_{t}$ to be a random variable that takes on the value of unity if the Fed changes the target rate during week $t$ and zero otherwise. Our first task is to

${ }^{1}$ Dufour and Engle (1999) have recently suggested some nonlinear generalizations of the ACD for which it would be interesting to explore the $\mathrm{ACH}$ analogs, such as

$$
\log \tilde{\psi}_{i}=\omega+\Sigma_{j=1}^{m}\left[\alpha_{j}\left(\tilde{u}_{i-j} / \tilde{\psi}_{i-j}\right)+\delta_{j}\left|\tilde{u}_{i-j} / \tilde{\psi}_{i-j}\right|\right]+\Sigma_{j=1}^{r} \log \tilde{\psi}_{i-j}
$$


rewrite expression (1) so that it is indexed by calendar time $t$ rather than by a count of the cumulative number of target changes $i$. Let $\left\{w_{1 t}\right\} t=1,2, \ldots, T$ be a sequence that, for any date $t$, records the date of the most recent change in the target as of week $t$ :

$$
w_{1 t}=t x_{t}+\left(1-x_{t}\right) w_{1, t-1} \quad \text { for } t=1,2, \ldots, T
$$

so that $w_{1 t}=t$ if the target changes on date $t$, and $w_{1 \tau}$ stays at $t$ for subsequent weeks $\tau$ until a new target change. Let $w_{2 t}$ denote the week of the target change before that:

$$
w_{2 t}=x_{t} w_{1, t-1}+\left(1-x_{t}\right) w_{2, t-1} \quad \text { for } t=1,2, \ldots, T
$$

so that $w_{2 t}=w_{1, t-1}$ if the target changes on date $t$ and $w_{2 \tau}$ stays at $w_{2, t-1}$ for subsequent weeks $\tau$ until a new target change. In general let $w_{j t}$ be the date of the $j^{\text {th }}$ most recent target as of date $t$ :

$$
w_{j t}=x_{t} w_{j-1, t-1}+\left(1-x_{t}\right) w_{j, t-1}
$$

for $j=2,3, \ldots$. Thus, in this notation, $w_{1, t-1}-w_{2, t-1}$ would correspond to the length of the most recent duration $\tilde{u}_{i}$ that has been completed prior to date $t$. Let $\psi_{t}$ denote the expected length of time separating the date of the most recent target change prior to date $t$ from the subsequent target change; that is, $\psi_{t}$ corresponds to the value of $\tilde{\psi}_{i}$ that is associated with calendar date $t$. In calendar time, expression (1) would then be written

$$
\psi_{t}=\omega+\sum_{j=1}^{m} \alpha_{j}\left(w_{j, t-1}-w_{j+1, t-1}\right)+\sum_{j=1}^{r} \beta_{j} \psi_{w_{j, t-1}} .
$$

Notice that expression (3) is a step function that only changes when a new event was observed the preceding week, i.e., only when $x_{t-1}=1$. 
Next consider the hazard rate $h_{t}$, which is defined as the conditional probability of a change in the target given $\mathcal{Y}_{t-1}$, which represents information observed as of time $t-1$ :

$$
h_{t}=P\left(x_{t}=1 \mid \mathcal{Y}_{t-1}\right)
$$

If the only information contained in $\mathcal{Y}_{t-1}$ were the dates of previous target changes, the hazard rate would not change until the next target change. In this case, one could calculate the expected length of time until the next target change as

$$
\sum_{j=1}^{\infty} j\left(1-h_{t}\right)^{j-1} h_{t}=1 / h_{t}
$$

and thus the hazard rate that is implied by the ACD model is

$$
h_{t}=1 / \psi_{t}
$$

The obvious advantage of describing the process in terms of calendar time and the hazard rate rather than in terms of event indexes and expected durations is that new information that appeared since the previous target change may also be relevant for predicting the timing of the next target change. A natural generalization of expression (5) is

$$
h_{t}=\frac{1}{\psi_{t}+\delta^{\prime} z_{t-1}}
$$

where $z_{t-1}$ denotes a vector of variables that is known at time $t-1$.

For reasons that will shortly become clear, we assume that the first element of $z_{t-1}$ is a constant and normalize $\delta_{1}$ relative to unity and likewise normalize $\omega$ to zero. Specifically, we work with a difference equation of the form of (3) without the constant term $\omega$ :

$$
q_{t}=\sum_{j=1}^{m} \alpha_{j}\left(w_{j, t-1}-w_{j+1, t-1}\right)+\sum_{j=1}^{r} \beta_{j} q_{w_{j, t-1}} .
$$


Notice that since the constant term $\omega$ has been dropped from (7), the average value of $q_{t}$ will not be $\bar{u}$, the average interval between target changes, but will instead be

$$
\bar{q}=\frac{\sum_{j=1}^{m} \alpha_{j} \bar{u}}{1-\sum_{j=1}^{r} \beta_{j}} .
$$

Hence the natural values to start up the recursion (7) would be

$$
\begin{gathered}
q_{t}=\bar{q} \quad \text { for } t=0,-1, \ldots \\
w_{j 0}-w_{j+1,0}=\bar{u} \quad \text { for } j=1, \ldots m .
\end{gathered}
$$

The hazard for observation $t$ is then obtained by iterating on (7) starting from (9) and (10) and then calculating

$$
h_{t}=\frac{1}{1+q_{t}+\delta^{\prime} z_{t-1}} .
$$

It might appear from the unit coefficient on $q_{t}$ in the denominator of (11) that this approach imposes a particular scale relation between durations $u_{i}$ and hazard rates $h_{t}$. However, this is not the case. For example, if one solves (7) for $m=r=1$ and substitutes the result into (11), the hazard can be written as

$$
h_{t}=\frac{1}{1+\delta^{\prime} z_{t-1}+\alpha \tilde{u}_{t}}
$$

where $\tilde{u}_{t}$ is a weighted average of past durations:

$$
\begin{gathered}
\tilde{u}_{t}=\left(w_{1, t-1}-w_{2, t-1}\right)+\beta\left(w_{2, t-1}-w_{3, t-1}\right)+\beta^{2}\left(w_{3, t-1}-w_{4, t-1}\right)+\ldots \\
+\beta^{\tau_{t-1}}\left(w_{\tau_{t, t-1}}-w_{\tau_{t}+1, t-1}\right)+\beta^{\tau} \bar{u}+\beta^{\tau_{t}+1} \bar{u} /(1-\beta)
\end{gathered}
$$


for $\tau_{t}+1$ the cumulative number of target changes that have been observed as of date $t$. Hence $\alpha$ is effectively a free parameter for translating from units of durations into a hazard rate.

Let $v_{t}=q_{t}+\delta^{\prime} z_{t-1}$ and notice that an important numerical objective is to ensure that $v_{t}$ is always positive. One way to do this is would be simply to replace $v_{t}$ by 0 whenever $v_{t}$ is negative. This has the drawback that the resulting function $h\left(v_{t}\right)$ is nondifferentiable at $v_{t}=0$, which could present problems for numerical optimization routines. We have had success using the following sigmoidal function to paste between negative and positive values of $v_{t}$ while maintaining continuous derivatives:

$$
m\left(v_{t}\right)= \begin{cases}0.0001 & v_{t} \leq 0 \\ 0.0001+2 \Delta v_{t}^{2} /\left(\Delta^{2}+v_{t}^{2}\right) & 0<v_{t}<\Delta . \\ 0.0001+v_{t} & v_{t} \geq \Delta\end{cases}
$$

Our empirical results below take $\Delta=0.1$.

The $\operatorname{ACH}(r, m)$ specification is then

$$
h_{t}=\frac{1}{1+m\left\{q_{t}+\delta^{\prime} z_{t-1}\right\}}
$$

for $m($.$) the function given in (12) and q_{t}$ calculated from (7) through (10).

Given the hazards it is then simple to evaluate the log likelihood function. Notice from (4) that the probability of observing $x_{t}$ given $\mathcal{Y}_{t-1}$ is

$$
g\left(x_{t} \mid \mathcal{Y}_{t-1} ; \theta_{1}\right)=\left(h_{t}\right)^{x_{t}}\left(1-h_{t}\right)^{1-x_{t}}
$$

for $\theta_{1}=\left(\delta^{\prime}, \alpha^{\prime}, \beta^{\prime}\right)^{\prime}$. Thus the conditional log likelihood is 


$$
\mathfrak{L}_{1}\left(\theta_{1}\right)=\sum_{t=1}^{T}\left\{x_{t} \log \left(h_{t}\right)+\left(1-x_{t}\right) \log \left(1-h_{t}\right)\right\}
$$

which can then be maximized numerically with respect to $\theta_{1}$. Robustness of numerical maximization routines likely requires further restricting $\alpha_{j} \geq 0, \beta_{j} \geq 0$, and $0 \leq \beta_{1}+\ldots+\beta_{r} \leq$ 1.

It is of interest to note that the $\mathrm{ACH}$ model includes the ACD model as a special case not only in terms of its implied value for the expected time separating target changes but also in terms of the value of the likelihood function (14) in the limit as the time interval used to discretize calendar time becomes arbitrarily small. This is demonstrated in the following section.

\section{Relation to Continuous-Time Models}

The previous section took the perspective that time is discrete. Suppose instead that time is continuous but we sample it in discrete intervals of length $\Delta$; (note that $\Delta$ was fixed at unity in the previous section). Then the log likelihood as calculated by the ACH model for the observations between the target change at date $w_{2 t}$ and the target change at date $w_{1 t}$ would be

$$
\sum_{\tau=w_{2 t}+\Delta}^{w_{1 t}}\left\{x_{\tau} \log \left(h_{\tau}(\Delta)\right)+\left(1-x_{\tau}\right) \log \left(1-h_{\tau}(\Delta)\right)\right\}
$$

where $h_{\tau}(\Delta)$ denotes the probability of a change between $\tau$ and $\tau+\Delta$ and where the summation over $\tau$ is in increments of $\Delta$. Note that from the definition of $w_{1 t}$ and $w_{2 t}$, the term 
$x_{\tau}$ in (15) is zero for all but the last $\tau$. Furthermore, if there are no exogenous covariates, then $h_{\tau}(\Delta)$ would be constant for all $\tau$, that is, $h_{\tau}(\Delta)=h_{w_{2 t}}(\Delta)$ for $\tau=w_{2 t}+\Delta, w_{2 t}+2 \Delta, \ldots, w_{1 t}$. Thus in the absence of exogenous covariates, expression (15) would become

$$
\begin{aligned}
\log \left(h_{w_{2 t}}(\Delta)\right) & +\log \left(1-h_{w_{2 t}}(\Delta)\right) \sum_{\tau=w_{2 t}+\Delta}^{w_{1 t}}\left(1-x_{\tau}\right) \\
= & \log \left(h_{w_{2 t}}(\Delta)\right)+\log \left(1-h_{w_{2 t}}(\Delta)\right) \frac{\left(w_{1 t}-w_{2 t}-\Delta\right)}{\Delta} .
\end{aligned}
$$

The probability $h_{\tau}(\Delta)$ of a change between $\tau$ and $\tau+\Delta$ of course vanishes as the time increment $\Delta$ becomes arbitrarily small. Suppose that associated with the sequence $\left\{h_{w_{2 t}}(\Delta)\right\}$ for succeedingly smaller values of $\Delta$ there exists a value $\psi_{w_{2 t}}$ such that,

$$
h_{w_{2 t}}(\Delta)=\psi_{w_{2 t}}^{-1} \Delta+o(\Delta)
$$

Expression (17) represents an assumption about the limiting continuous-time probability law governing events that is often described as the Poisson postulate (see for example Chiang, 1980, p. 250). Notice by Taylor's theorem,

$$
\log \left[1-h_{w_{2 t}}(\Delta)\right] \frac{\left(w_{1 t}-w_{2 t}-\Delta\right)}{\Delta}=-\left(w_{1 t}-w_{2 t}\right) \psi_{w_{2 t}}^{-1}+O(\Delta) .
$$

Substituting (18) into (16), it is clear that (16) differs from

$$
\log \left[h_{w_{2 t}}(\Delta)\right]-\left(w_{1 t}-w_{2 t}\right) \psi_{w_{2 t}}^{-1}
$$

by $O(\Delta)$. Thus if we use the $\mathrm{ACH}$ model to evaluate the log likelihood for the observed target 
changes between $w_{2 t}$ and $w_{1 t}$ for the fixed interval $\Delta=1$, and if (17) is a good approximation for $\Delta=1$, then

$$
\begin{gathered}
\sum_{\tau=w_{2 t}+1}^{w_{1 t}}\left\{x_{\tau} \log \left[h_{\tau}(1)\right]+\left(1-x_{\tau}\right) \log \left[1-h_{\tau}(1)\right]\right\} \\
\simeq \log \left(\psi_{w_{2 t}}^{-1}\right)-\left(w_{1 t}-w_{2 t}\right) \psi_{w_{2 t}}^{-1}
\end{gathered}
$$

Suppose we were to index observations not by time but by the occurrence of changes in the funds rate target. Thus observation $i=1$ would correspond to the first observed target change, $i=2$ to the second observed target change, and $i=N$ to the last observed target change. Let $\tilde{u}_{i}$ denote the length of time between the $i-1$ and the $i$ target changes, so that if the $i$ th target change occurred at date $w_{1 t}$, then $\tilde{u}_{i}=w_{1 t}-w_{2 t}$. Let $\widetilde{\psi}_{i}$ denote the value of the $\psi$ parameter relevant for the $i$ th change, namely $\widetilde{\psi}_{i}=\psi_{w_{2 t}}$. Then (19) implies that

$$
\sum_{\tau=1}^{w_{1 T}}\left\{x_{\tau} \log \left[h_{\tau}(1)\right]+\left(1-x_{\tau}\right) \log \left[1-h_{\tau}(1)\right\} \simeq \sum_{i=1}^{N}\left\{\log \widetilde{\psi}_{i}^{-1}-\frac{\widetilde{u}_{i}}{\widetilde{\psi}_{i}}\right\}\right.
$$

where the approximation becomes arbitrarily good as the discrete sampling frequency on which the left-hand side is based becomes finer and finer. The right-hand side of (20) will be recognized as identical to equation (17) in Engle (1999), which is the form of the log likelihood as calculated under the exponential autoregressive conditional duration specification. In the ACD model, the parameter $\widetilde{\psi}_{i}$ has the interpretation of the expected length of time between events, that is, $\widetilde{\psi}_{i}$ is the expectation of $\widetilde{u}_{i}$ conditional on $\widetilde{u}_{i-1}, \ldots, \widetilde{u}_{1}$. Thus $(20)$ reproduces the familiar result that one can reparameterize the likelihood function for such processes 
equivalently in terms of durations or in terms of hazards, where from (17) the expected duration is essentially the reciprocal of the single period $(\Delta=1)$ hazard.

\section{Predicting the value of the target}

Predicting the value of the Federal funds rate target for any given week requires answering two questions. The first is the question analyzed up to this point: Is the Fed going to change the target this week or leave it in place? Second, if the Fed does change the target, by how much will the target change? Such a time series is sometimes described as a marked point process, in which "points" refers to the dates at which the target is changed (dates $t$ for which $\left.x_{t}=1\right)$ and "marks" refers to the sizes of the changes when they occur. Let $y_{t}$ be the mark, or the magnitude of the target change if one occurs in week $t$. As before, let $z_{t-1}$ denote a vector of exogenous variables such as production, prices, and unemployment, that influence the Fed's decision on the target, and let $\mathcal{Y}_{t}$ denote the history of observations through date $t$,

$$
\mathcal{Y}_{t}=\left(x_{t}, y_{t}, z_{t}^{\prime}, x_{t-1}, y_{t-1}, z_{t-1}^{\prime}, \ldots, x_{1}, y_{1}, z_{1}^{\prime}\right)^{\prime}
$$

Our task is to model the joint probability distribution of $x_{t}$ and $y_{t}$ conditional on the past. Without loss of generality this probability can be factored as:

$$
f\left(x_{t}, y_{t} \mid \mathcal{Y}_{t-1} ; \theta_{1}, \theta_{2}\right)=g\left(x_{t} \mid \mathcal{Y}_{t-1} ; \theta_{1}\right) q\left(y_{t} \mid x_{t}, \mathcal{Y}_{t-1} ; \theta_{2}\right)
$$

Our objective is to choose $\theta_{1}$ and $\theta_{2}$ so as to maximize the log likelihood, 


$$
\sum_{t=1}^{T} \log f\left(x_{t}, y_{t} \mid \mathcal{Y}_{t-1} ; \theta_{1}, \theta_{2}\right)=\mathfrak{L}_{1}\left(\theta_{1}\right)+\mathfrak{L}_{2}\left(\theta_{2}\right)
$$

where

$$
\mathfrak{L}_{1}\left(\theta_{1}\right)=\sum_{t=1}^{T} \log g\left(x_{t} \mid \mathcal{Y}_{t-1} ; \theta_{1}\right)
$$

is described in equation (14) while

$$
\mathfrak{L}_{2}\left(\theta_{2}\right)=\sum_{t=1}^{T} \log q\left(y_{t} \mid x_{t}, \mathcal{Y}_{t-1} ; \theta_{2}\right)
$$

If $\theta_{1}$ and $\theta_{2}$ have no parameters in common, then maximization of (23) is equivalent to maximization of (24) and (25) separately. If they do have parameters in common, then separate maximization would not be efficient but would still lead to consistent estimates. ${ }^{2}$

Consider, then, the determinants of the marks, or the size of a target change given that one occurs. Target changes typically occur in discrete increments of 25 basis points, though changes as small as 6.25 basis points were sometimes observed prior to 1990. The discreteness of the target changes suggests the use of an ordered response model as in Hausman, Lo, and MacKinlay (1992). Since target changes only occur at particular dates, it is easiest to describe this model by indexing observations by events $i$ rather than dates $t$. Following the notation of the previous section, we will use tildes to denote variables that are indexed by events and no tildes for variables that are indexed by dates.

\footnotetext{
${ }^{2}$ An interesting approach that models $\theta_{1}$ and $\theta_{2}$ jointly is the autoregressive multinomial framework of Engle and Russell (1999).
} 
Let $i=1$ correspond to the first target change in the sample, $i=2$ to the second target change, and $i=N$ to the last target change. Let $\widetilde{y}_{i}$ denote the magnitude of the $i$ th target change and let $\widetilde{w}_{i}$ denote a vector of variables observed in the week prior to the $i$ th target change that may have influenced the Fed's decision of how much to change the target; if the $i$ th target change occurs at date $t$, then $\widetilde{w}_{i}$ is a subset of the vector $\mathcal{Y}_{t-1}$ defined in equation (21). We hypothesize the existence of an unobserved latent variable $\widetilde{y}_{i}^{*}$ which depends on $\widetilde{w}_{i}$ according to

$$
\widetilde{y}_{i}^{*}=\widetilde{w}_{i}^{\prime} \pi+\widetilde{\varepsilon}_{i}
$$

where $\widetilde{\varepsilon}_{i} \mid \widetilde{w}_{i} \sim$ i.i.d. $N(0,1)$.

Suppose that there are $m$ different discrete amounts by which the Fed may change the target. Denote the possible changes in the target by $s_{1}, s_{2}, \ldots, s_{m}$ where $s_{1}<s_{2}<\ldots<s_{m}$. We hypothesize that the observed discrete target change $\widetilde{y}_{i}$ is related to the latent continuous variable $\widetilde{y}_{i}^{*}$ according to

$$
\widetilde{y}_{i}=\left\{\begin{array}{lll}
s_{1} & \text { if } & \widetilde{y}_{i}^{*} \in\left(-\infty, c_{1}\right] \\
s_{2} & \text { if } & \widetilde{y}_{i}^{*} \in\left(c_{1}, c_{2}\right] \\
\vdots & & \\
s_{m} & \text { if } & \widetilde{y}_{i}^{*} \in\left(c_{m-1}, \infty\right)
\end{array}\right.
$$

where $c_{1}<c_{2}<\ldots<c_{m}$. Notice that the probability that the target changes by $s_{j}$ is given by 


$$
\operatorname{Pr}\left(\widetilde{y}_{i}=s_{j} \mid \widetilde{w}_{i}\right)=\operatorname{Pr}\left(c_{j-1}<\widetilde{w}_{i}^{\prime} \pi+\widetilde{\varepsilon}_{i} \leq c_{j}\right)
$$

for $j=1,2, \ldots, m$, with $c_{0}=-\infty$ and $c_{m}=\infty$. If $\Phi(z)$ denotes the probability that a standard Normal variable takes on a value less than or equal to $z$, then these probabilities can be written

$$
\begin{aligned}
\operatorname{Pr}\left(\widetilde{y}_{i}=\right. & \left.s_{j} \mid \widetilde{w}_{i}\right) \\
& = \begin{cases}\Phi\left(c_{1}-\widetilde{w}_{i}^{\prime} \pi\right) & \text { for } j=1 \\
\Phi\left(c_{j}-\widetilde{w}_{i}^{\prime} \pi\right)-\Phi\left(c_{j-1}-\widetilde{w}_{i}^{\prime} \pi\right) & \text { for } j=2,3, \ldots, m-1 \\
1-\Phi\left(c_{m-1}-\widetilde{w}_{i}^{\prime} \pi\right) & \text { for } j=m .\end{cases}
\end{aligned}
$$

Note that this specification implies that, the bigger the value of $\widetilde{w}_{i}^{\prime} \pi$, the greater the probability that the latent variable $\widetilde{y}_{i}^{*}$ takes on a value in a higher bin and so the greater the probability of observing a big increase in the target $\widetilde{y}_{i}$. Thus if an increase in the unemployment rate tends to cause the Fed to lower the target, then we would expect the coefficient in $\pi$ that multiplies the unemployment rate to be negative.

Let $\ell\left(\widetilde{y}_{i} \mid \widetilde{w}_{i} ; \theta_{2}\right)$ denote the natural log of the probability of observing $\widetilde{y}_{i}$ conditional on $\widetilde{w}_{i}$,

$$
\ell\left(\widetilde{y}_{i} \mid \widetilde{w}_{i} ; \theta_{2}\right)= \begin{cases}\log \left[\Phi\left(c_{1}-\widetilde{w}_{i}^{\prime} \pi\right)\right] & \text { if } \quad \widetilde{y}_{i}=s_{1} \\ \log \left[\Phi\left(c_{j}-\widetilde{w}_{i}^{\prime} \pi\right)-\Phi\left(c_{j-1}-\widetilde{w}_{i}^{\prime} \pi\right)\right] & \text { if } \quad \widetilde{y}_{i}=s_{2}, s_{3}, \ldots, s_{m-1} \\ \log \left[1-\Phi\left(c_{m-1}-\widetilde{w}_{i}^{\prime} \pi\right)\right] & \text { if } \quad \widetilde{y}_{i}=s_{m}\end{cases}
$$

where $\theta_{2}=\left(\pi^{\prime}, c_{1}, c_{2}, \ldots, c_{m-1}\right)^{\prime}$. The conditional log likelihood of the marks (the second term in equation (23)) can thus be written 


$$
\mathcal{L}_{2}\left(\theta_{2}\right)=\sum_{t=1}^{T} \log q\left(y_{t} \mid x_{t}, \mathcal{Y}_{t-1} ; \theta_{2}\right)=\sum_{i=1}^{N} \ell\left(\widetilde{y}_{i} \mid \widetilde{w}_{i} ; \theta_{2}\right)
$$

where we have used the fact that $\operatorname{Pr}\left(y_{t}=0 \mid x_{t}=0\right)=1$. The vector of population parameters is then estimated by maximizing (29) subject to the constraint that $c_{j}>c_{j-1}$ for $j=$ $1,2, \ldots, m-1$.

\section{$5 \quad$ Data and Institutional Framework}

The U.S. Federal Reserve requires banks to hold deposits in their accounts with the Fed so as to exceed a minimum required level based on the volume of transactions deposits held by the banks' customers. Calculation of whether a bank satisfies these reserve requirements is based in part on the bank's average Federal Reserve deposits held over a two-week period beginning on a Thursday and ending on a Wednesday. If the Fed sells Treasury securities to the public, the payments it receives from banks' customers force banks to reduce their Fed deposits. Given the need to continue to meet reserve requirements, banks are then forced to try to borrow the reserves from other banks on the Fed funds market or from the Fed at the Fed's discount window, or to manage with a lower level of excess reserves. Banks' aversion to the second and third options causes the equilibrium interest rate on loans of Federal funds to be bid up in response to the initial sale of securities by the Fed. The Trading Desk of the Federal Reserve Bank of New York carefully monitors banks' reserve requirements and available Fed deposits, and implements purchases or sales of Treasury securities (open 
market operations) in order to achieve a particular target for the Federal funds rate. ${ }^{3}$

The raw data for our study are the dates and sizes of Federal funds target changes for 1984-1997 compiled by Glenn Rudebusch (1995) and updated by Volker Wieland. ${ }^{4}$ These values are reported in Table 1. The nature of the target and details of its implementation have changed considerably during our sample period. In the early part of the sample, the directive for the Trading Desk at the Federal Reserve Bank of New York was often framed in terms of a desired level of "reserve pressure," interpreted as an expected level of borrowing from the Fed's discount window (see for example Heller, 1988, or Meulendyke, 1998, pp. 139142). Given a relatively stable positive relation between discount window borrowing and the Fed funds rate, this usually translated fairly directly into a target for the Fed funds rate itself. However, a borrowed reserves target requires frequent adaptation of the procedure to changes in market conditions. Table 1 reveals that, in the early part of the sample, target changes almost always came on Thursday, either at the beginning of a new two-week reserve maintenance period or halfway through in response to new market information. Moreover, the target was characterized by small and frequent adjustments over this period. Dates of FOMC meetings and FOMC conference calls are given in Tables 2 and 3. In the latter part of our sample, the FOMC directives were almost always implemented immediately. In the early part of our sample, the FOMC directives usually were not implemented until the week following the FOMC meeting, and additional changes often came much later, evidently

\footnotetext{
${ }^{3}$ See Feinman (1993) or Meulendyke (1998) for further details.

${ }^{4}$ We thank Volker Wieland for graciously providing us with these data.
} 
reflecting decisions made by the Chairman of the Federal Reserve under the broad guidelines of earlier FOMC directives.

In principle, it would be possible to apply our $\mathrm{ACH}$ model to daily data with careful modeling of these strong day-of-the-week effects. We felt that little was lost by converting our data to a weekly series, where for compatibility with the reserve-requirement cycle we define a week as beginning on a Thursday and ending on a Wednesday. The target we associate with any given week is the value for the target on the final Wednesday of that seven-day period. For eight weeks in our sample, there were two target changes within this seven-day period, which in our constructed data were treated as a single large change.

Small, frequent changes in the target were perhaps a necessary aspect of the borrowed reserves operating procedure, but they served another function as well, namely helping to provide for Fed secrecy. When Chairman Paul Volcker allowed the Fed funds rate to reach $20 \%$ in 1981, he did not want the evening news reporting how much the Fed had deliberately decided to kick up interest rates each day. The target changes in the early part of our sample were virtually never announced publicly.

This does not mean that the market did not know about the changes in the target. On the contrary, if the Fed made a large injection of reserves on a day when the Fed funds rate was already trading below the previous target, market participants would quite accurately and immediately know that the target had been lowered. Indeed, the Wall Street Journal would report each day whether the target had been raised or lowered. Cook and Hahn (1989) constructed a time series for the target based exclusively on market inferences as 
reported in the Wall Street Journal, and the series is quite close to the official Trading Desk figures used here. Thus, Fed "secrecy" did not mean keeping the market confused about what the Fed was up to; indeed, giving the market a clear understanding of the FOMC target helped the Fed considerably to implement its goals. Instead, "secrecy" meant that the nature of the inference was sufficiently arcane and subtle that detailed Fed directives were not reported by the nonfinancial press and thus the Fed was insulated slightly from political criticism for its weekly decisions.

Secrecy issues aside, a borrowed reserves operating procedure ultimately had to be disbanded for the simple reason that banks became virtually unwilling to borrow from the discount window regardless of the level of the Federal funds rate. Discount window borrowing came to be viewed by a bank's creditors as a signal of financial weakness, inducing banks to pay almost any cost to avoid it. The dashed line in the top panel of Figure 1 plots monthly values for the level of discount window borrowing for adjustment purposes. By 1991 discount window adjustment borrowing had essentially fallen to zero. Internal Fed documents reveal that by 1989 the Fed was increasingly coming to ignore the borrowed reserves target and effectively target the Fed funds rate directly. ${ }^{5}$

When Alan Greenspan became Chairman in 1987, the Fed initially continued the policy of borrowed reserves targeting and small, semi-secret target changes. A key event for the transition to the current operating procedure occurred on November 22, 1989, when the Fed added reserves at a time when the rate was below its 8-1/2\% target. The market interpreted

\footnotetext{
${ }^{5}$ Federal Reserve Bank of New York, 1990, pp. 34-35, 56-57.
} 
this as a signal that the target had been lowered, and a Fed policy change was announced in the business press (Wall Street Journal, November 24, 1989, p. 2; November 28, 1989, p. 1). In fact the Fed had not changed its target, but had added reserves because of its analysis of the demand for borrowed reserves. This market reaction prompted a re-examination of Fed procedure. One change shows up quite dramatically in the series for the assumption that the Trading Desk made about the level of discount window borrowing in forming its implementation of monetary policy each day, which appears as the solid line in the top panel of Figure 1. ${ }^{6} \quad$ Up until November 1989 this borrowing assumption series tracked adjustment borrowing as best it could. After November, the Fed essentially assumed zero adjustment borrowing, so that the borrowing assumption series becomes nearly identical to the level of seasonal borrowing (Panels B and $\mathrm{C}$ of Figure 1). One further sees no change in the target that is smaller than 25 basis points after November 1989, and no repeat of the market confusion in interpreting Fed policy. Indeed, since 1994, the Fed has announced its target Fed funds rate in complete openness.

\section{Empirical Results}

\subsection{ACH estimates}

We first fit the simple $\operatorname{ACD}(1,1)$ model to our full weekly data set for Federal funds rate target changes (March 1, 1984 to June 5, 1997) by maximizing the hazard-based likelihood (14) with $h_{t}$ given by (5) and $\psi_{t}$ given by (3). The implied ACD model is as follows, with

\footnotetext{
${ }^{6}$ Data for the Trading Desk borrowing assumption are from Thornton (1998). We thank Daniel Thornton for graciously sharing these data.
} 
standard errors based on second derivatives of the log likelihood in parentheses:

$$
\psi_{t}=\underset{(1.18)}{0.29}+\underset{(0.067)}{0.131}\left(w_{1, t-1}-w_{2, t-1}\right)+\underset{(0.066)}{0.889} \psi_{w_{1, t-1}} \quad \log \text { likelihood }=-275.97
$$

These parameter estimates imply a highly persistent ACD process; indeed, (30) implies that durations between events admit an $\operatorname{ARMA}(1,1)$ representation with autoregressive coefficient equal to $0.131+0.889=1.02$, an explosive process. A little exploration with additional explanatory variables for the ACH model quickly revealed that this nonstationarity can be attributed entirely to changes in Fed operating procedure detailed in the previous section. We concluded that it is necessary to model the data as having been generated from two different regimes, the first corresponding to the borrowed-reserves target regime (March 1,1984 to November 23, 1989) and the second to the explicit funds-rate target regime (November 30, 1989 to June 5, 1997)

For each subsample we considered a number of variables to include in the vector $z_{t-1}$ in equation (13) to try to predict the timing of changes in the target. The variables we considered fall in three general categories: (1) variables reflecting the overall state of the macroeconomy that may influence interest rates and the Fed's broad policy objectives, such as inflation, unemployment, output growth, and the budget deficit; (2) monetary and financial aggregates, such as the growth rate of M2, long-term interest rates, and the spread between the 6-month Treasury bill and the Fed funds rate; (3) variables specific to the Trading Desk operating procedures described in the previous section, such as the dates of FOMC meetings, Strongin's (1995) measure of borrowed reserve pressure, the size of the previous target change, and the duration $(t-1)-w_{1, t-1}$ since the previous change. Our final 
models keep only those parameters that are statistically significant.

Table 4 reports maximum likelihood estimates for the first subsample. The estimates suggest persistent serial correlation in the durations or hazards, with $\alpha+\beta=0.97$. Of the variables other than lagged durations that we investigated, only two appear to be statistically significant. The variable $F O M C_{t-1}$ is a dummy variable that takes the value of 1 if there was an FOMC meeting during week $t-1$ and is zero otherwise, while $f_{t-1}$ is simply the lagged value of the effective Fed funds rate.

The week following an FOMC meeting was considerably more likely to see a target change than other weeks during this period. Specifically, the average value for $q_{t}$ in this subsample is 1.36 and the average value for $f_{t-1}$ is 6.41 . These imply a typical hazard of $1 /(1+1.36+4.99-3.40)=0.25$, or a one in four chance that the Fed would change its target next week. By contrast, in the week following an FOMC meeting, this probability goes up to $1 /(1+1.36+4.99-3.40-1.58)=0.42$. A high level of the Fed funds rate also makes the Fed more likely to adjust its target quickly. The highest levels of the Fed funds surpass $9 \%$ at the beginning and end of the subsample, in which case the probability of a target change rises to $1 /(1+1.36+4.99-4.77)=0.39$, even with no FOMC meeting. Both these results are entirely consistent with the description of the way the Fed implemented and adjusted the target during this period. What is perhaps surprising is that forecasting a target change over this period appears to be entirely a matter of modeling the way the Fed responded to immediate reserve pressures and the fact of an FOMC meeting; none of the macroeconomic variables we investigated helped improve the forecasts of target changes. 
By contrast, we found no evidence of serial correlation in the durations in the 1989-1997 subsample. Table 5 reports parameter estimates for a hazard model driven entirely by the explanatory variables $z_{t-1}$ with no role for lagged durations. Over this period, the Fed has tended to implement target changes during the week of FOMC meetings rather than the week after. The other variable that we found useful for forecasting target changes over this period is $\left|S P 6_{t-1}\right|$, the absolute value of the spread between the effective Federal funds rate and the six month Treasury bill rate.

To get a sense of these estimates, the average absolute spread over this subperiod is 0.34 , implying a typical hazard of $1 /(1+25.59-2.28)=0.041$; the Fed is extremely unlikely to change the target during a week without an FOMC meeting, under the current regime. With an FOMC meeting, the probability of a target change rises to $1 /(1+25.59-2.28-19.27)=$ 0.20. If there is an FOMC meeting in week $t$ and the previous week the spread had been 100 basis points or higher, a change in the target is virtually a sure thing.

\subsection{Ordered probit estimates}

Next we turn to empirical estimates of our ordered probit model for the marks, or the size of Fed target changes when they occur. Our first step was to consolidate the number of possible categories for changes in the target. Historical changes occurred in increments of 6.25 basis points until December 1990 and in increments of 25 basis points afterwards. We consolidated these earlier data (along with the one change of 75 basis points on November

$15,1994)$ as follows. If $\widetilde{y}_{i}^{\#}$ denotes the actual value for the $i^{\text {th }}$ target change in Table 1 , then our analyzed data $\widetilde{y}_{i}$ were defined as 


$$
\widetilde{y}_{i}=\left\{\begin{array}{lll}
-0.50 & \text { if }-\infty< & \widetilde{y}_{i}^{\#} \leq-0.5 \\
-0.25 & \text { if }-0.4375 \leq & \widetilde{y}_{i}^{\#}<-0.125 \\
0.00 & \text { if }-0.125 \leq & \widetilde{y}_{i}^{\#}<0.0625 \\
0.25 & \text { if } 0.0625 \leq \widetilde{y}_{i}^{\#}<0.375 \\
0.50 & \text { if } 0.4375 \leq \widetilde{y}_{i}^{\#}<\infty
\end{array} .\right.
$$

We then maximized the likelihood function $\mathcal{L}_{2}\left(\theta_{2}\right)$ in expression $(29)$ with respect to $\pi$, the coefficients on the explanatory variables in (26), and the threshold parameters $c_{j}$ in (28). The explanatory variables $\widetilde{w}_{i}$ use the value of the variable for the week prior to the target change. Results are reported in Table 6 . Most of the ACH explanatory variables proved insignificant for explaining the size of target changes and were dropped. We find an extremely strong effect of $y_{w_{1, t-1}}$; if the previous change raised the target, then this week's change is much more likely to be an increase than a decrease. We find an equally dramatic negative influence of the $f_{t-1}-T B 6_{t-1}$ spread; if the Fed funds rate is above the 6-month Treasury bill rate, then we can expect the Fed to lower the target.

\section{Forecast evaluations}

One advantage of the $\mathrm{ACH}$ framework is that it generates a closed-form expression for the one-period-ahead forecast of the target $i_{t+1}$ based on observation of $\mathcal{Y}_{t}=\left(i_{t}, z_{t}^{\prime}, i_{t-1}, z_{t-1}^{\prime}, \ldots\right)^{\prime}$ where $z_{t}=\left(f_{t}, S P 6_{t}\right)^{\prime}$. Specifically,

$$
E\left(i_{t+1} \mid \mathcal{Y}_{t}\right)=\left(1-h_{t+1}\right) i_{t}+h_{t+1} \sum_{j=1}^{5}\left(i_{t}+s_{j}\right)\left[\Phi\left(c_{j}-\mathcal{Y}_{t}^{\prime} \pi\right)-\Phi\left(c_{j-1}-\mathcal{Y}_{t}^{\prime} \pi\right)\right]
$$


where $h_{t+1}$ is calculated from (13) and (7)-(10), $s_{j}=(0.25)(j-3), c_{j}$ are as given in Table 6 with $c_{0}=-\infty$ and $c_{5}=\infty$ and $\mathcal{Y}_{t}^{\prime} \pi=2.60\left(i_{w_{1, t}}-i_{w_{2}, t}\right)-0.42 S P 6_{t}$.

Multiperiod-ahead forecasts are substantially less convenient. One first requires forecasts of the explanatory variables $z_{t+j}$. These can be generated with a VAR (with contemporaneous values of $i_{t}$ included), estimated for each of the two sub-samples we consider at the November 23, 1989 break-point. Thus, for example, our forecasting equations for $f_{t}$ and $S P 6_{t}$ estimated by OLS over $t=3 / 8 / 84$ to $11 / 23 / 89$ are (standard errors in parenthesis):

$$
\begin{gathered}
f_{t}=\underset{(0.091)}{0.218}+\underset{(0.069)}{0.347} f_{t-1}-\underset{(0.047)}{0.042} S P 6_{t-1}+\underset{(0.124)}{0.415} i_{t}-\underset{(0.130)}{0.219} i_{t-1}, \\
S P 6_{t}=\underset{(0.098)}{-0.184}-\underset{(0.073)}{0.492} f_{t-1}+\underset{(0.050)}{0.886} S P 6_{t-1}-\underset{(0.132)}{0.065} i_{t}+\underset{(0.139)}{0.549} i_{t-1} .
\end{gathered}
$$

Unfortunately, the forecast $E\left(i_{t+j+1} \mid \mathcal{Y}_{t+j}\right)$ in (32) is a nonlinear function of $\mathcal{Y}_{t+j}$, so simulation methods are necessary for multiperiod-ahead forecasts. Specifically, (32) is derived from a discrete probability distribution for $i_{t+1} \mid \mathcal{Y}_{t}$ and one can generate a value $i_{t+1}^{(1)}$ from this distribution. If one further assumes that the errors in (33) and (34) are bivariate Gaussian, then, given this value $i_{t+1}^{(1)}$, can generate a value $z_{t+1}^{(1)}$ from (33) and (34), which represents a draw from the distribution of $z_{t+1} \mid \mathcal{Y}_{t}$. Using $z_{t+1}^{(1)}$ one can again use the distribution behind (32) to generate a value $i_{t+2}^{(1)}$, which now represents a draw from the distribution $i_{t+2} \mid \mathcal{Y}_{t}$. Iterating on this sequence produces at step $j$ a value $i_{t+j}^{(1)}$ which represents a single draw from the distribution $f\left(i_{t+j} \mid \mathcal{Y}_{t}\right)$. One can then go back to the beginning to generate a second value $i_{t+1}^{(2)}$ from $f\left(i_{t+1} \mid \mathcal{Y}_{t}\right)$ as in $(32)$ and iterate to obtain a second draw $i_{t+j}^{(2)}$ from $f\left(i_{t+j} \mid \mathcal{Y}_{t}\right)$. The average value from $M$ simulations, $M^{-1} \sum_{m=1}^{M} i_{t+j}^{(m)}$, represents the forecast $E\left(i_{t+j} \mid \mathcal{Y}_{t}\right)$. 
Most of the macro literature has focused on monthly values for the effective Fed funds rate rather than the weekly Fed funds target as here. For purposes of comparison, we estimated a monthly VAR similar to that used by Evans and Marshall (1998). The EvansMarshall VAR uses monthly data on the logarithm of nonagricultural employment $(E M)$; the logarithm of personal consumption expenditures deflator in chain-weighted 1992 dollars $(P)$; the change in the index of sensitive materials prices $(P C O M)$; the effective Federal funds rate $(f)$; the ratio of nonborrowed reserves plus extended credit to total reserves $(N B R X)$; and the log growth rate of the monetary aggregate M2 (M2). The model has twelve lags and is estimated over the sample January 1965 to September 1997. The mean squared errors for 1- to 12-month ahead forecasts for this VAR are reported in the first column of Table 7.

We then ask, How good a job can our weekly model of the Fed funds target do at predicting the monthly values of the effective Fed funds rate? We used our ACH and ordered-probit model to forecast the value that the Fed funds target would assume the last week of month $\tau+j$ based on information available as of the last week of month $\tau$. We then calculated the squared difference between this forecast for the target and the actual value for the effective Fed funds rate for month $\tau+j$ and report the MSE's in the second column of Table 7 .

This would seem to be a tough test for our model, given that (a) the estimation criteria for the VAR is minimizing the MSE whereas the estimation criteria for our model is maximizing the likelihood function; and (b) the VAR is specifically optimized for forecasting monthly values of $f$ whereas ours is designed to describe weekly changes in the target. Even so, 
attention to the short-run institutional details of Fed policy seems to yield substantially superior forecasts of the monthly $f$ at horizons up to 6 months. Beyond 6 months, the monthly VAR begins to do a significantly better job than our weekly model. ${ }^{7}$

We conclude that the $\mathrm{ACH}$ specification is worth considering as a realistic description of the dynamics of the Fed funds target. It thus seems of interest to revisit some of the policy questions that have been addressed using linear VAR's, to which we turn in the next section.

\section{Estimating the effects of monetary policy shocks}

A great number of papers have attempted to measure the effects of monetary policy based on linear vector autoregressions. Let $\mathbf{y}_{\tau}$ denote a vector of macro variables for month $\tau$; in the Evans and Marshall (1998) VAR, $\mathbf{y}_{\tau}=\left(E M_{\tau}, P_{\tau}, P C O M_{\tau}, f_{\tau}, N B R X_{\tau}, M 2_{\tau}\right)^{\prime}$. Let $\mathbf{y}_{1 \tau}=\left(E M_{\tau}, P_{\tau}, P C O M_{\tau}\right)^{\prime}$ denote the variables that come before the effective Fed funds rate $f_{\tau}$ and $\mathbf{y}_{2 \tau}=\left(N B R X_{\tau}, M 2_{\tau}\right)^{\prime}$ the variables that come after. An estimate of the effects of a monetary policy shock based on a Cholesky decomposition of the residual variancecovariance matrix would calculate the impulse-response function,

$$
\frac{\partial E\left(\mathbf{y}_{\tau+s} \mid f_{\tau}, \mathbf{y}_{1 \tau}, \mathbf{y}_{\tau-1}, \mathbf{y}_{\tau-2}, \ldots\right)}{\partial f_{\tau}} .
$$

This is equivalent to finding the effect on $\mathbf{y}_{\tau+s}$ of an orthogonalized shock to $f_{\tau}$, where an orthogonalized shock is defined as

$$
u_{\tau}^{f}=f_{\tau}-E\left(f_{\tau} \mid \mathbf{y}_{1 \tau}, \mathbf{y}_{\tau-1}, \mathbf{y}_{\tau-2}, \ldots\right) .
$$

\footnotetext{
${ }^{7}$ See Rudebusch (1995) for further discussion of the properties of forecasts of the target over intermediate horizons.
} 
Note that the shock can be written as

$$
u_{\tau}^{f}=f_{\tau}-f_{\tau-1}-\left[E\left(f_{\tau} \mid \mathbf{y}_{1 \tau}, \mathbf{y}_{\tau-1}, \mathbf{y}_{\tau-2}, \ldots\right)-f_{\tau-1}\right] .
$$

A positive value for $u_{\tau}^{f}$ could thus come from two sources. On the one hand, the Fed could have changed the target $\left(f_{\tau}-f_{\tau-1}>0\right)$ when no change was expected $\left(E\left(f_{\tau} \mid \mathbf{y}_{1 \tau}, \mathbf{y}_{\tau-1}, \mathbf{y}_{\tau-2}, \ldots\right)-\right.$ $\left.f_{\tau-1}=0\right)$. On the other hand, the Fed may not have changed the target $\left(f_{\tau}-f_{\tau-1}=0\right)$ even though the VAR had expected a drop $\left(E\left(f_{\tau} \mid \mathbf{y}_{1 \tau}, \mathbf{y}_{\tau-1}, \mathbf{y}_{\tau-2}, \ldots\right)-f_{\tau-1}<0\right)$. Either event would produce a positive $u_{\tau}^{f}$. The two events are predicted to have the same effect if the data were generated from a linear VAR.

In a nonlinear model such as our $\mathrm{ACH}$ specification, however, the two events are not forced to have the same effects, and it is an interesting exercise to see what the model says about their respective consequences. To do so, we start with the linear VAR,

$$
\mathbf{y}_{\tau}=\mathbf{c}+\boldsymbol{\Phi}_{1} \mathbf{y}_{\tau-1}+\boldsymbol{\Phi}_{2} \mathbf{y}_{\tau-2}+\ldots+\boldsymbol{\Phi}_{12} \mathbf{y}_{\tau-12}+\boldsymbol{\varepsilon}_{\tau}
$$

We estimate the parameters $\left(\mathbf{c}, \boldsymbol{\Phi}_{1}, \boldsymbol{\Phi}_{2}, \ldots, \boldsymbol{\Phi}_{12}\right)$ by OLS equation by equation. We also need the forecast of $\mathbf{y}_{2 \tau}$ given $\mathbf{y}_{1 \tau}$ and $i_{\tau}$. This can be obtained by estimating the following system by OLS, one equation at a time,

$$
\mathbf{y}_{2 \tau}=\mathbf{d}+\mathbf{d}_{1} i_{\tau}+\mathbf{D}_{0} \mathbf{y}_{1 \tau}+\mathbf{B}_{1} \mathbf{y}_{\tau-1}+\mathbf{B}_{2} \mathbf{y}_{\tau-2}+\ldots+\mathbf{B}_{12} \mathbf{y}_{\tau-12}+\mathbf{u}_{2 \tau}
$$

where $\mathbf{d}_{1}$ in the Evans-Marshall example is a $(2 \times 1)$ vector, $\mathbf{D}_{0}$ is a $(2 \times 3)$ matrix, and $\mathbf{B}_{j}$ are $(2 \times 6)$ matrices. Given any hypothesized value for $i_{\tau}$ and the historical values for $\mathbf{y}_{1 \tau}, \mathbf{y}_{\tau-1}, \mathbf{y}_{\tau-2}, \ldots$, one can then calculate the forecast $\tilde{\mathbf{y}}_{2 \tau \mid \tau}\left(i_{\tau}\right)$ from (36). Collect these 
forecasts along with the historical $\mathbf{y}_{1 \tau}$ and the hypothesized $i_{\tau}$ in a vector

$$
\tilde{\mathbf{y}}_{\tau \mid \tau}\left(i_{\tau}\right)=\left(\mathbf{y}_{1 \tau}^{\prime}, i_{\tau}, \tilde{\mathbf{y}}_{2 \tau \mid \tau}^{\prime}\left(i_{\tau}\right)\right)^{\prime}
$$

The one-step-ahead VAR forecast conditional on the hypothetical $i_{\tau}$ is:

$$
\hat{E}\left(\mathbf{y}_{\tau+1} \mid i_{\tau}, \mathbf{y}_{1 \tau}, \mathbf{y}_{\tau-1}, \mathbf{y}_{\tau-2}, \ldots\right)=\mathbf{c}+\boldsymbol{\Phi}_{1} \tilde{\mathbf{y}}_{\tau \mid \tau}\left(i_{\tau}\right)+\boldsymbol{\Phi}_{2} \mathbf{y}_{\tau-1}+\ldots+\boldsymbol{\Phi}_{12} \mathbf{y}_{\tau-11} .
$$

We then replace the fourth element of the vector of conditional forecasts in (38), corresponding to the forecast of the effective Fed funds rate $f_{\tau+1}$, with the forecast target rate for the last week of month $\tau+1$. This forecast is calculated as in the previous section based on historical values of variables available at date $\tau$, with the historical value for the target at date $\tau$ replaced by the hypothesized value of $i_{\tau}$. Call the resulting vector $\tilde{\mathbf{y}}_{\tau+1 \mid \tau}\left(i_{\tau}\right)$. Next, we use the VAR coefficients to generate two-step-ahead forecasts conditional on $i_{\tau}$ :

$$
\hat{E}\left(\mathbf{y}_{\tau+2} \mid i_{\tau}, \mathbf{y}_{1 \tau}, \mathbf{y}_{\tau-1}, \mathbf{y}_{\tau-2}, \ldots\right)=\mathbf{c}+\boldsymbol{\Phi}_{1} \tilde{\mathbf{y}}_{\tau+1 \mid \tau}\left(i_{\tau}\right)+\boldsymbol{\Phi}_{2} \tilde{\mathbf{y}}_{\tau \mid \tau}\left(i_{\tau}\right)+\ldots+\boldsymbol{\Phi}_{12} \mathbf{y}_{\tau-10} .
$$

We again replace the fourth element of (39) with the forecast of $i_{\tau+2}$ implied by the ACH model and call the result $\tilde{\mathbf{y}}_{\tau+2 \mid \tau}\left(i_{\tau}\right)$. Iterating in this manner, we can calculate $\tilde{\mathbf{y}}_{\tau+j \mid \tau}\left(i_{\tau}\right)$, which summarizes the dynamic consequences of the forecast time path for $i_{\tau}, i_{\tau+1}, \ldots$ implied by the ACH model for other macroeconomic variables of interest.

To measure the consequences of the first term in (35), we ask, What difference does it make if the Fed raises the target by 25 basis points during month $\tau\left(i_{\tau}=i_{\tau-1}+0.25\right)$ compared to if it had kept the target constant $\left(i_{\tau}=i_{\tau-1}\right)$ ? We then normalize the answer in units of a derivative, as

$$
(0.25)^{-1}\left[\left.\tilde{\mathbf{y}}_{\tau+j \mid \tau}\left(i_{\tau}\right)\right|_{i_{\tau}=i_{\tau-1}+0.25}-\left.\tilde{\mathbf{y}}_{\tau+j \mid \tau}\left(i_{\tau}\right)\right|_{i_{\tau}=i_{\tau-1}}\right] .
$$


If we had not replaced the fourth element of (38) and (39) at each iteration with the ACH forecast, the resulting value in (40) would not depend on $\tau$ or $i_{\tau-1}$ and would be numerically identical to the standard VAR impulse-response function based on the Cholesky decomposition. As is, the value of (40) does depend on $\tau$ and $i_{\tau-1}$, and to report results we therefore average (40) over the historical values $\tau=1, \ldots, T$ and $\mathbf{y}_{1}, \ldots, \mathbf{y}_{T}$ in our sample.

The second term in (35) asks, What would happen if we predicted a change in the target but none occurred? Letting $\hat{\imath}_{\tau \mid \tau-1}$ denote the forecast for the target in month $\tau$ based on historical information available at date $\tau-1$, we thus calculate

$$
\omega_{\tau}\left[\left.\tilde{\mathbf{y}}_{\tau+j \mid \tau}\left(i_{\tau}\right)\right|_{i_{\tau}=i_{\tau-1}}-\left.\tilde{\mathbf{y}}_{\tau+j \mid \tau}\left(i_{\tau}\right)\right|_{i_{\tau}=\hat{i}_{\tau \mid \tau-1}}\right]
$$

where

$$
\omega_{\tau}=\left\{\begin{array}{ll}
\left(i_{\tau-1}-\hat{\imath}_{\tau \mid \tau-1}\right)^{-1} & \text { if }\left|i_{\tau-1}-\hat{\imath}_{\tau \mid \tau-1}\right|>0.02 \\
0 & \text { otherwise }
\end{array} .\right.
$$

The effect of the weight $\omega_{\tau}$ in (41) is to ignore observations for which no change was expected and to rescale positive or negative forecast errors into units comparable to (40). Again if we had not replaced the VAR forecasts of $f_{\tau+j}$ with the $\mathrm{ACH}$ forecasts of $i_{\tau+j}$, the magnitude in (41) would be not depend on $\tau$ and would be numerically identical to the VAR impulseresponse function.

Figure 2 calculates the effects of three different kinds of monetary policy shocks. The solid line is the linear VAR impulse-response function, describing the effects of a 100-basispoint increase in $f_{\tau}$ on each of the five other variables in $\mathbf{y}_{\tau+j}$ for $j=0$ to 11 months. This replicates the conventional results - an increase in the Federal funds rate is associated with 
an initial decrease in nonborrowed reserves and in M2, and is followed within 6 months by a decline in employment and prices. The short-dashed line records the average values of (40) over all the dates $\tau$ in our sample, which we interpret as the answer to the question, What happens when the Federal Reserve deliberately raises its target for the Federal funds rate? The effects are qualitatively similar to the VAR impulse-response function, but quantitatively are much bigger - a policy change implies a bigger contraction in NBRX or M2 than the orthogonalized VAR innovations $u_{\tau}^{f}$, and the negative consequences for employment and prices are much bigger as well. The long-dashed line records the average values of (41), which answers the question, What happens if one would have predicted that the Fed was going to lower the target, but in fact it did not? The results are completely different, and suggest that the Fed's decision not to lower the target is typically an endogenous response to the Fed's accurate predictions of a strong economy and surging prices and money demand. The linear VAR, which essentially is an average of these two scenarios, thus appears to be mixing together the answers to two very different experiments.

\section{Conclusions}

This paper introduced the autoregressive conditional hazard model for generating a timevarying serially dependent probability forecast for a discrete event such as a change in the Federal funds rate targeted by the Federal Reserve. The advantage over the closely related autoregressive conditional duration specification is the ability to incorporate new information on other variables into the forecast. 
We find that the change in Federal Reserve operating procedures from borrowed reserves targeting over 1984-1989 to an explicit Fed funds rate target since 1989 show up quite dramatically through this investigation. We also find that, in our nonlinear model, "innovations" in monetary policy are not all the same. Specifically, an increase in the target results in a much more dramatic effect on employment and prices than does the prediction of a target decrease that fails to materialize. 


\section{References}

Chiang, Chin Long, (1980). An Introduction to Stochastic Processes and Their Applications. New York: Krieger Publishing Co.

Cook, Timothy and Thomas Hahn, (1989), "The Effect of Changes in the Federal Funds Rate Target on Market Interest Rates in the 1970's," Journal of Monetary Economics 24, 331-51.

Davutyan, Nurhan, and William R. Parke (1995), "The Operations of the Bank of England, 1890-1908: A Dynamic Probit Approach," Journal of Money, Credit, and Banking 27, 1099-1112.

Dueker, Michael, (1998), "Conditional heteroscedasticity in Qualitative Response Models of Time Series: A Gibbs Sampling Approach Applied to the Bank Prime Rate," working paper, Federal Reserve Bank of St. Louis.

Dufour, Alfonso, and Robert F. Engle, (1999), "The ACD Model: Predictability of the Time between Consecutive Trades," working paper, UCSD.

Eichengreen, Barry, Mark W. Watson, and Richard S. Grossman, (1985), "Bank Rate Policy under the Interwar Gold Standard: A Dynamic Probit Model," Economic Journal 95, 725-745.

Engle, Robert F., (1999), "The Econometrics of Ultra - High Frequency Data," Econometrica, forthcoming.

, and Jeffrey R. Russell, (1997), "Forecasting the Frequency of Changes in Quoted Foreign Exchange Prices with the ACD Model," Journal of Empirical Finance, $12,187-212$.

, and ___ (1998), "Autoregressive Conditional Duration: A New Model for Irregularly Spaced Transaction Data," Econometrica 66, 1127-1162.

, and

(1999), "The Econometric Analysis of Discrete-Valued Irregularly-Spaced Financial Transactions Data Using a New Autoregressive Conditional Multinomial Model," working paper, UCSD.

Evans, Charles L., and David A. Marshall (1998), "Monetary Policy and the Term Structure of Nominal Interest Rates: Evidence and Theory," Carnegie-Rochester Conference Series on Public Policy, 49, 53-111.

Federal Reserve Bank of New York, (1990), "Monetary Policy and Open Market Operations During 1989," A Report prepared for the Federal Open Market Committee by the Open Market Group of the Federal Reserve Bank of New York, March 1990, confidential. 
Feinman, Joshua, (1993), "Estimating the Open Market Desk's Daily Reaction Function," Journal of Money, Credit, and Banking, 25, 231-47.

Hausman, Jerry A., Andrew W. Lo and A. Craig Mackinlay, (1992), "An Ordered Probit Analysis of Transaction Stock Prices," Journal of Financial Economics 31, 319-379.

Heller, H. Robert, (1988), "Implementing Monetary Policy," Federal Reserve Bulletin July, 419-429.

Lee, Lung-fie, (1999), "Estimation of Dynamic and ARCH Tobit Models," Journal of Econometrics, 92, 355-390.

McCulloch, Robert, and Peter E. Rossi, (1994), "An Exact Likelihood Analysis of the Multinomial Probit Model," Journal of Econometrics, 64, pp. 207-240.

Meulendyke, Ann Marie, (1998), U. S. Monetary Policy and Financial Markets, Federal Reserve Bank of New York.

Rudebusch, Glenn D., (1995), "Federal Reserve Interest Rate Targeting, Rational Expectations and the Term structure," Journal of Monetary Economics 35, 245-74. Erratum: (December 1995) 36:679.

Sims, Christopher A., (1992), "Interpreting the Macroeconomic Time Series Facts: The Effects of Monetary Policy," European Economic Review 36, 975-1000.

Strongin, Steven, (1995), "The Identification of Monetary Policy Disturbances. Explaining the Liquidity Puzzle," Journal of Monetary Economics 35, 463-497.

Thornton, Daniel L., (1998), "The Federal Reserve's Operating Procedure, Nonborrowed Reserves, Borrowed Reserves, and the Liquidity Effect," working paper, Federal Reserve Bank of St. Louis. 
Table 1 - Calendar of Changes in the Federal Funds Rate Target

\begin{tabular}{|c|c|c|c|c|c|c|c|c|c|}
\hline $\begin{array}{c}\text { Date of } \\
\text { Change }\end{array}$ & $\begin{array}{r}\text { Target } \\
\text { Value } \\
\end{array}$ & $\begin{array}{r}\text { Target } \\
\text { Change }\end{array}$ & $\begin{array}{r}\text { Duration } \\
\text { in days } \\
\end{array}$ & $\begin{array}{r}\text { Day of } \\
\text { the Week }\end{array}$ & $\begin{array}{r}\text { Date of } \\
\text { Change }\end{array}$ & $\begin{array}{r}\text { Target } \\
\text { Value }\end{array}$ & $\begin{array}{r}\text { Target } \\
\text { Change }\end{array}$ & $\begin{array}{r}\text { Duration } \\
\text { in days }\end{array}$ & $\begin{array}{l}\text { Day of } \\
\text { the Week }\end{array}$ \\
\hline 1-Mar-84 & 9.5 & na & & Thursday & 28-Jan-88 & 6.625 & -0.1875 & 85 & Thursday \\
\hline 15-Mar-84 & 9.875 & 0.375 & 14 & Thursday & 11-Feb-88 & 6.5 & -0.125 & 14 & Thursday \\
\hline 22-Mar-84 & 10 & 0.125 & 7 & Thursday & 30-Mar-88 & 6.75 & 0.25 & 48 & Wednesday \\
\hline 29-Mar-84 & 10.25 & 0.25 & 7 & Thursday & 9-May-88 & 7 & 0.25 & 40 & Monday \\
\hline 5-Apr-84 & 10.5 & 0.25 & 7 & Thursday & 25-May-88 & 7.25 & 0.25 & 16 & Wednesday \\
\hline 14-Jun-84 & 10.625 & 0.125 & 70 & Thursday & 22-Jun-88 & 7.5 & 0.25 & 28 & Wednesday \\
\hline 21-Jun-84 & 11 & 0.375 & 7 & Thursday & 19-Jul-88 & 7.6875 & 0.1875 & 27 & Tuesday \\
\hline 19-Jul-84 & 11.25 & 0.25 & 28 & Thursday & 8-Aug-88 & 7.75 & 0.0625 & 20 & Monday \\
\hline 9-Aug-84 & 11.5625 & 0.3125 & 21 & Thursday & 9-Aug-88 & 8.125 & 0.375 & 1 & Tuesday \\
\hline 30-Aug-84 & 11.4375 & -0.125 & 21 & Thursday & $20-O c t-88$ & 8.25 & 0.125 & 72 & Thursday \\
\hline $20-$ Sep-84 & 11.25 & -0.1875 & 21 & Thursday & 17-Nov-88 & 8.3125 & 0.0625 & 28 & Thursday \\
\hline 27-Sep-84 & 11 & -0.25 & 7 & Thursday & 22-Nov-88 & 8.375 & 0.0625 & 5 & Tuesday \\
\hline 4-Oct-84 & 10.5625 & -0.4375 & 7 & Thursday & 15-Dec-88 & 8.6875 & 0.3125 & 23 & Thursday \\
\hline $11-$ Oct-84 & 10.5 & -0.0625 & 7 & Thursday & 29-Dec-88 & 8.75 & 0.0625 & 14 & Thursday \\
\hline $18-O c t-84$ & 10 & -0.5 & 7 & Thursday & 5-Jan-89 & 9 & 0.25 & 7 & Thursday \\
\hline 8-Nov-84 & 9.5 & -0.5 & 21 & Thursday & 9-Feb-89 & 9.0625 & 0.0625 & 35 & Thursday \\
\hline 23-Nov-84 & 9 & -0.5 & 15 & Friday & 14-Feb-89 & 9.3125 & 0.25 & 5 & Tuesday \\
\hline 6-Dec-84 & 8.75 & -0.25 & 13 & Thursday & $23-F e b-89$ & 9.5625 & 0.25 & 9 & Thursday \\
\hline 20-Dec-84 & 8.5 & -0.25 & 14 & Thursday & 24-Feb-89 & 9.75 & 0.1875 & 1 & Friday \\
\hline 27-Dec-84 & 8.125 & -0.375 & 7 & Thursday & 4-Мay-89 & 9.8125 & 0.0625 & 69 & Thursday \\
\hline 24-Jan-85 & 8.25 & 0.125 & 28 & Thursday & 6-Jun-89 & 9.5625 & -0.25 & 33 & Tuesday \\
\hline $14-F e b-85$ & 8.375 & 0.125 & 21 & Thursday & 7-Jul-89 & 9.3125 & -0.25 & 31 & Friday \\
\hline 21-Feb-85 & 8.5 & 0.125 & 7 & Thursday & 27-Jul-89 & 9.0625 & -0.25 & 20 & Thursday \\
\hline 21-Mar-85 & 8.625 & 0.125 & 28 & Thursday & 10-Aug-89 & 9 & -0.0625 & 14 & Thursday \\
\hline 28-Mar-85 & 8.5 & -0.125 & 7 & Thursday & 18-Oct-89 & 8.75 & -0.25 & 69 & Wednesday \\
\hline 18-Apr-85 & 8.375 & -0.125 & 21 & Thursday & 6-Nov-89 & 8.5 & -0.25 & 19 & Monday \\
\hline 25-Apr-85 & 8.25 & -0.125 & 7 & Thursday & 20-Dec-89 & 8.25 & -0.25 & 44 & Wednesday \\
\hline 16-Маy-85 & 8.125 & -0.125 & 21 & Thursday & 13-Jul-90 & 8 & -0.25 & 205 & Friday \\
\hline 20-May-85 & 7.75 & -0.375 & 4 & Monday & 29-Oct-90 & 7.75 & -0.25 & 108 & Monday \\
\hline 11-Jul-85 & 7.6875 & -0.0625 & 52 & Thursday & 14-Nov-90 & 7.5 & -0.25 & 16 & Wednesday \\
\hline 25-Jul-85 & 7.75 & 0.0625 & 14 & Thursday & 7-Dec-90 & 7.25 & -0.25 & 23 & Friday \\
\hline 22-Aug-85 & 7.8125 & 0.0625 & 28 & Thursday & 19-Dec-90 & 7 & -0.25 & 12 & Wednesday \\
\hline 29-Aug-85 & 7.875 & 0.0625 & 7 & Thursday & 9-Jan-91 & 6.75 & -0.25 & 21 & Wednesday \\
\hline 6-Sep-85 & 8 & 0.125 & 8 & Friday & 1-Feb-91 & 6.25 & -0.5 & 23 & Friday \\
\hline 18-Dec-85 & 7.75 & -0.25 & 103 & Wednesday & 8-Mar-91 & 6 & -0.25 & 35 & Friday \\
\hline 7-Mar-86 & 7.25 & -0.5 & 79 & Friday & 30-Apr-91 & 5.75 & -0.25 & 53 & Tuesday \\
\hline 10-Apr-86 & 7.125 & -0.125 & 34 & Thursday & 6-Aug-91 & 5.5 & -0.25 & 98 & Tuesday \\
\hline 17-Apr-86 & 7 & -0.125 & 7 & Thursday & 13-Sep-91 & 5.25 & -0.25 & 38 & Friday \\
\hline 24-Apr-86 & 6.75 & -0.25 & 7 & Thursday & 31-Oct-91 & 5 & -0.25 & 48 & Thursday \\
\hline 22-May-86 & 6.8125 & 0.0625 & 28 & Thursday & 6-Nov-91 & 4.75 & -0.25 & 6 & Wednesday \\
\hline 5-Jun-86 & 6.875 & 0.0625 & 14 & Thursday & 6-Dec-91 & 4.5 & -0.25 & 30 & Friday \\
\hline 11-Jul-86 & 6.375 & -0.5 & 36 & Friday & 20-Dec-91 & 4 & -0.5 & 14 & Friday \\
\hline 14-Aug-86 & 6.3125 & -0.0625 & 34 & Thursday & 9-Apr-92 & 3.75 & -0.25 & 111 & Thursday \\
\hline 21-Aug-86 & 5.875 & -0.4375 & 7 & Thursday & 2-Jul-92 & 3.25 & -0.5 & 84 & Thursday \\
\hline 4-Dec-86 & 6 & 0.125 & 105 & Thursday & 4-Sep-92 & 3 & -0.25 & 64 & Friday \\
\hline 30-Apr-87 & 6.5 & 0.5 & 147 & Thursday & 4-Feb-94 & 3.25 & 0.25 & 518 & Friday \\
\hline 21-Маy-87 & 6.75 & 0.25 & 21 & Thursday & 22-Mar-94 & 3.5 & 0.25 & 46 & Tuesday \\
\hline 2-Jul-87 & 6.625 & -0.125 & 42 & Thursday & 18-Apr-94 & 3.75 & 0.25 & 27 & Monday \\
\hline 27-Aug-87 & 6.75 & 0.125 & 56 & Thursday & 17-May-94 & 4.25 & 0.5 & 29 & Tuesday \\
\hline 3-Sep-87 & 6.875 & 0.125 & 7 & Thursday & 16-Aug-94 & 4.75 & 0.5 & 91 & Tuesday \\
\hline 4-Sep-87 & 7.25 & 0.375 & 1 & Friday & 15-Nov-94 & 5.5 & 0.75 & 91 & Tuesday \\
\hline 24-Sep-87 & 7.3125 & 0.0625 & 20 & Thursday & 1-Feb-95 & 6 & 0.5 & 78 & Wednesday \\
\hline $22-O c t-87$ & 7.125 & -0.1875 & 28 & Thursday & 6-Jul-95 & 5.75 & -0.25 & 155 & Thursday \\
\hline 28-Oct-87 & 7 & -0.125 & 6 & Wednesday & 19-Dec-95 & 5.5 & -0.25 & 166 & Tuesday \\
\hline \multirow[t]{2}{*}{ 4-Nov-87 } & 6.8125 & -0.1875 & 7 & Wednesday & 31-Jan-96 & 5.25 & -0.25 & 43 & Wednesday \\
\hline & & & & & 25-Mar-97 & 5.50 & 0.25 & 419 & Tuesday \\
\hline
\end{tabular}


Table 2: Dates of Federal Open Markets Committee Meetings

\begin{tabular}{|c|c|c|c|}
\hline Year & FOMC Dates & Year & FOMC Dates \\
\hline \multirow[t]{8}{*}{1984} & January 30-31 & 1991 & February 5-6 \\
\hline & March 26-27 & & March 26 \\
\hline & May 21-22 & & May 14 \\
\hline & July $16-17$ & & July 2-3 \\
\hline & August 21 & & August 20 \\
\hline & October 2 & & October 1 \\
\hline & November 7 & & November 5 \\
\hline & December $17-18$ & & December 17-18 \\
\hline \multirow[t]{8}{*}{1985} & February 12-13 & 1992 & February 4-5 \\
\hline & March 26 & & March 31 \\
\hline & May 21 & & May 19 \\
\hline & July 9-10 & & June $30-31$ \\
\hline & August 20 & & August 18 \\
\hline & October 1 & & October 16 \\
\hline & November 4-5 & & November 17 \\
\hline & December $16-17$ & & December 22 \\
\hline \multirow[t]{8}{*}{1986} & February 11-12 & 1993 & February 2-3 \\
\hline & April 1 & & March 23 \\
\hline & May 20 & & May18 \\
\hline & July 8-9 & & July 6-7 \\
\hline & August 19 & & August 17 \\
\hline & September 23 & & September 21 \\
\hline & November 5 & & November 16 \\
\hline & December $15-16$ & & December 21 \\
\hline \multirow[t]{8}{*}{1987} & February 10-11 & 1994 & February 3-4 \\
\hline & March 31 & & March 22 \\
\hline & May 19 & & May 17 \\
\hline & July 7 & & July 5-6 \\
\hline & August 18 & & August 16 \\
\hline & September 22 & & September 27 \\
\hline & November 3 & & November 15 \\
\hline & December $15-16$ & & December 20 \\
\hline \multirow[t]{8}{*}{1988} & February 9-10 & 1995 & January 31-1 \\
\hline & March 29 & & March 28 \\
\hline & May 17 & & May 23 \\
\hline & June $29-30$ & & July 5-6 \\
\hline & August 16 & & August 22 \\
\hline & September 30 & & September 26 \\
\hline & November 1 & & November 15 \\
\hline & December 13-14 & & December 19 \\
\hline \multirow[t]{8}{*}{1989} & February 6-7 & 1996 & January 30-31 \\
\hline & March 28 & & March 26 \\
\hline & May 16 & & May 21 \\
\hline & July 5-6 & & July 2-3 \\
\hline & August 22 & & August 20 \\
\hline & October 3 & & September 24 \\
\hline & November 14 & & November 13 \\
\hline & December 18-19 & & December 17 \\
\hline \multirow[t]{8}{*}{1990} & February 6-7 & 1997 & February 4-5 \\
\hline & March 27 & & March 25 \\
\hline & May 15 & & May 20 \\
\hline & July 2-3 & & July 1-2 \\
\hline & August 21 & & August 19 \\
\hline & October 2 & & September 30 \\
\hline & November 13 & & November 12 \\
\hline & December $17-18$ & & \\
\hline
\end{tabular}


Table 3: Dates of FOMC Telephone Conference Calls

\begin{tabular}{|c|c|c|c|}
\hline Year & Date of Call & Year & Date of Call \\
\hline 1984 & $\begin{array}{l}\text { January } 11 \\
\text { March } 20 \\
\text { October } 18 \\
\text { December } 7\end{array}$ & \multirow[t]{3}{*}{1989} & $\begin{array}{l}\text { February } 23 \\
\text { May } 31 \\
\text { June } 5 \\
\text { July } 26\end{array}$ \\
\hline 1985 & $\begin{array}{l}\text { January } 18 \\
\text { September } 10 \\
\text { September } 23\end{array}$ & & $\begin{array}{l}\text { October } 16 \\
\text { October } 17 \\
\text { October } 18\end{array}$ \\
\hline 1986 & $\begin{array}{l}\text { January } 17 \\
\text { April } 21\end{array}$ & & $\begin{array}{l}\text { November } 6 \\
\text { November } 27\end{array}$ \\
\hline \multirow[t]{2}{*}{1987} & \multirow{2}{*}{$\begin{array}{l}\text { February } 23 \\
\text { April } 29 \\
\text { October } 20 \\
\text { October } 21 \\
\text { October } 22 \\
\text { October } 23 \\
\text { October } 26 \\
\text { October } 27 \\
\text { October } 28 \\
\text { October } 29 \\
\text { October } 30\end{array}$} & 1990 & $\begin{array}{l}\text { January } 16 \\
\text { April } 11 \\
\text { August } 6 \\
\text { September } 7 \\
\text { September } 17 \\
\text { December } 7\end{array}$ \\
\hline & & \multirow[t]{2}{*}{1991} & $\begin{array}{l}\text { January } 9 \\
\text { February } 1 \\
\text { March } 26 \\
\text { April } 12 \\
\text { April } 30\end{array}$ \\
\hline \multirow[t]{3}{*}{1988} & \multirow[t]{3}{*}{$\begin{array}{l}\text { January } 5 \\
\text { May } 6 \\
\text { May } 24 \\
\text { June } 22 \\
\text { July } 19 \\
\text { August } 5 \\
\text { August } 9 \\
\text { October } 17 \\
\text { November } 22\end{array}$} & & $\begin{array}{l}\text { May } 1 \\
\text { June } 10 \\
\text { June } 24 \\
\text { August } 5 \\
\text { September } 13 \\
\text { October } 30 \\
\text { December } 2 \\
\text { December } 20\end{array}$ \\
\hline & & 1992 & $\begin{array}{l}\text { January } 9 \\
\text { March } 11 \\
\text { July } 2 \\
\text { December } 14\end{array}$ \\
\hline & & 1993 & $\begin{array}{l}\text { January } 6 \\
\text { February } 18 \\
\text { March } 1 \\
\text { October } 5 \\
\text { October } 15 \\
\text { October } 22\end{array}$ \\
\hline
\end{tabular}


Table 4

Parameter Estimates for ACH(1,1) Model for 1984-1989

\begin{tabular}{cccc}
\hline \hline parameter & variable & estimate & (standard error) \\
\hline$\alpha$ & $w_{1, t-1}-w_{2, t-1}$ & 0.085 & $(0.058)$ \\
$\beta$ & $q_{w_{1, t-1}}$ & 0.886 & $(0.109)$ \\
$\delta_{1}$ & constant & 4.991 & $(2.305)$ \\
$\delta_{2}$ & $F O M C_{t-1}$ & -1.579 & $(0.691)$ \\
$\delta_{3}$ & $f_{t-1}$ & -0.530 & $(0.212)$ \\
\hline \hline
\end{tabular}

log likelihood: -162.27 
Table 5

Parameter Estimates for $\mathrm{ACH}(0,0)$ Model for 1989-1997

\begin{tabular}{cccc}
\hline \hline parameter & variable & estimate & (standard error) \\
\hline$\delta_{1}$ & constant & 25.59 & $(6.38)$ \\
$\delta_{2}$ & $F O M C_{t}$ & -19.27 & $(6.35)$ \\
$\delta_{3}$ & $\left|S P 6_{t-1}\right|$ & -6.70 & $(2.61)$ \\
\hline \hline
\end{tabular}

log likelihood: -85.39 


\section{Table 6}

Parameter Estimates for Ordered Probit Model for 1984-1997

\begin{tabular}{cccc}
\hline \hline parameter & variable & estimate & (standard error) \\
\hline$\pi_{1}$ & $y_{w_{1, t-1}}$ & 2.60 & $(0.41)$ \\
$\pi_{2}$ & $S P 6_{t-1}$ & -0.42 & $(0.22)$ \\
$c_{1}$ & & -1.85 & $(0.23)$ \\
$c_{2}$ & -0.38 & $(0.19)$ \\
$c_{3}$ & & 0.05 & $(0.19)$ \\
$c_{4}$ & & 1.56 & $(0.24)$ \\
\hline \hline
\end{tabular}

log likelihood: -122.97 


\section{Table 7}

Mean Squared Errors for 1-12 Step-Ahead Forecasts Based on the ACH model and the VAR from Evans and Marshall (1998)

\begin{tabular}{lcc}
\hline \hline Forecast horizon & VAR & ACH \\
\hline 1 Step Ahead & 0.1052 & 0.0242 \\
2 Steps Ahead & 0.2051 & 0.0837 \\
3 Steps Ahead & 0.3201 & 0.1849 \\
4 Steps Ahead & 0.4410 & 0.3222 \\
5 Steps Ahead & 0.5625 & 0.4905 \\
6 Steps Ahead & 0.6843 & 0.6790 \\
7 Steps Ahead & 0.8000 & 0.8944 \\
8 Steps Ahead & 0.9093 & 1.1556 \\
9 Steps Ahead & 1.0031 & 1.3531 \\
10 Steps Ahead & 1.1139 & 1.9112 \\
11Steps Ahead & 1.2435 & 2.3862 \\
12 Steps Ahead & 1.4048 & 2.8686 \\
\hline \hline
\end{tabular}


Adjustment borrowing and borrowing assumption
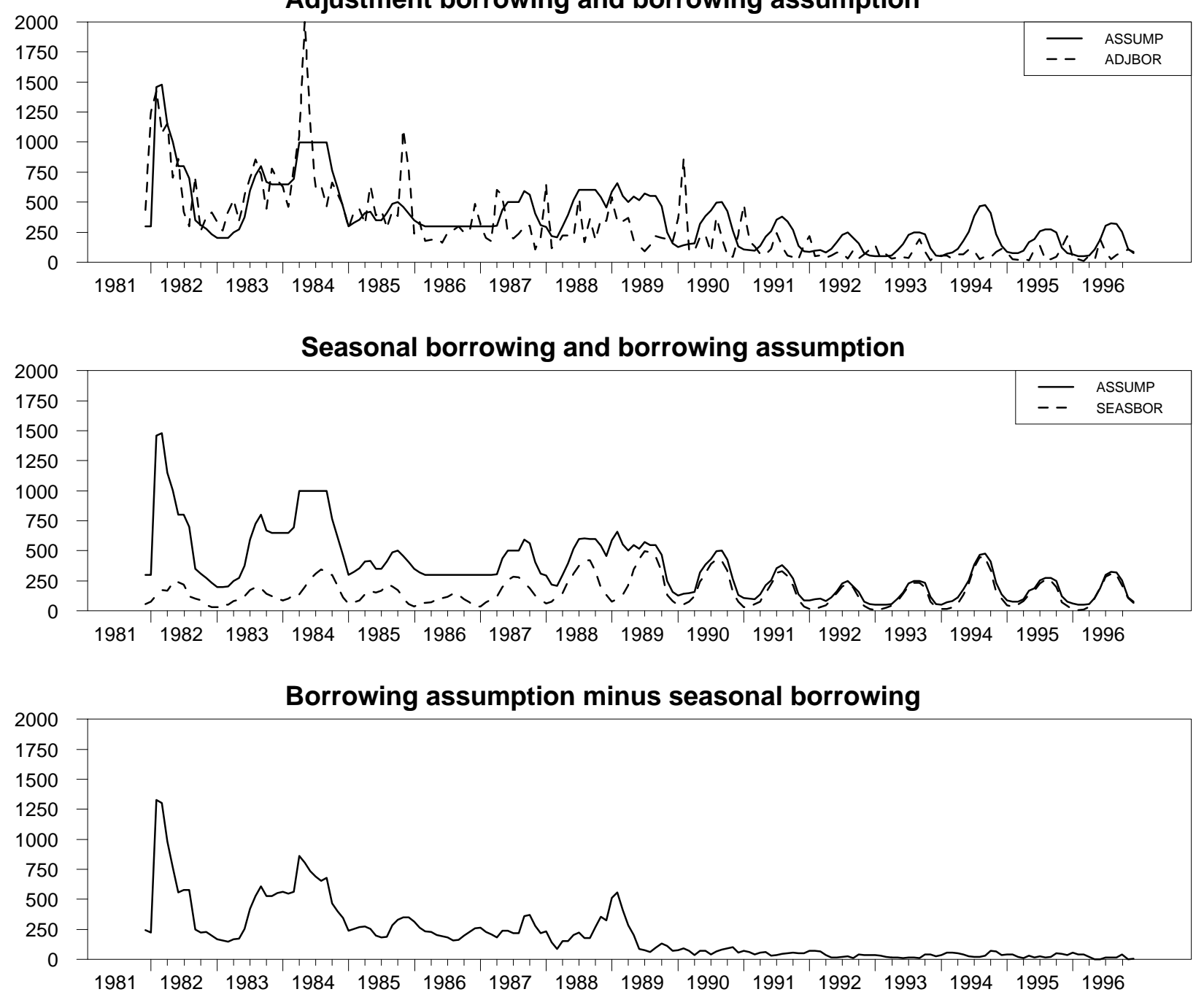
Figure 2 -Responses to Different Measures of Innovations in the Federal Funds Rate
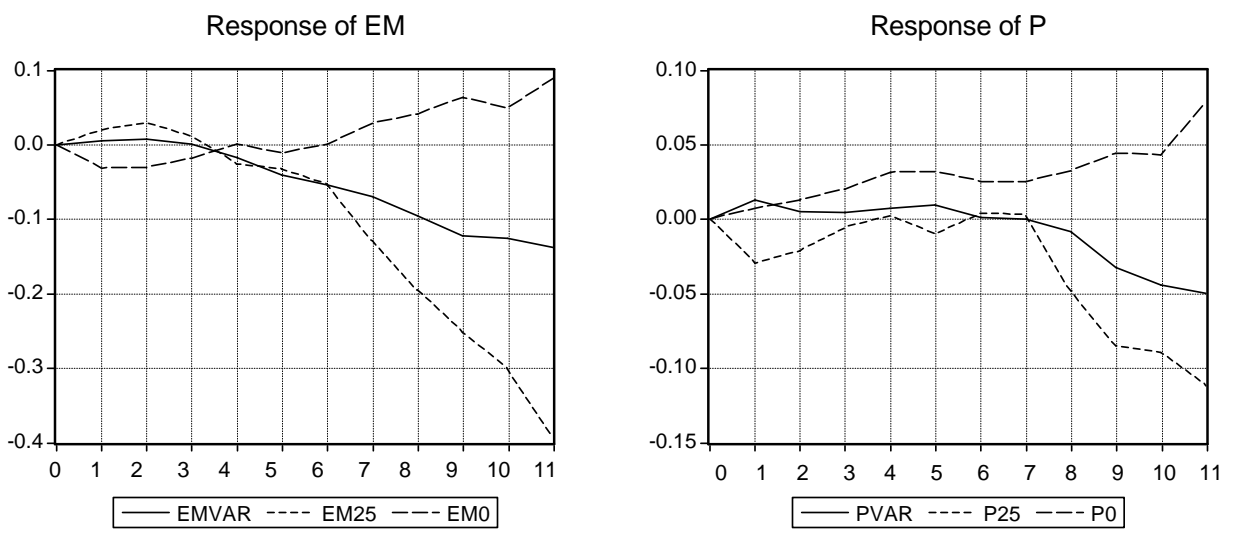

Response of PCOM
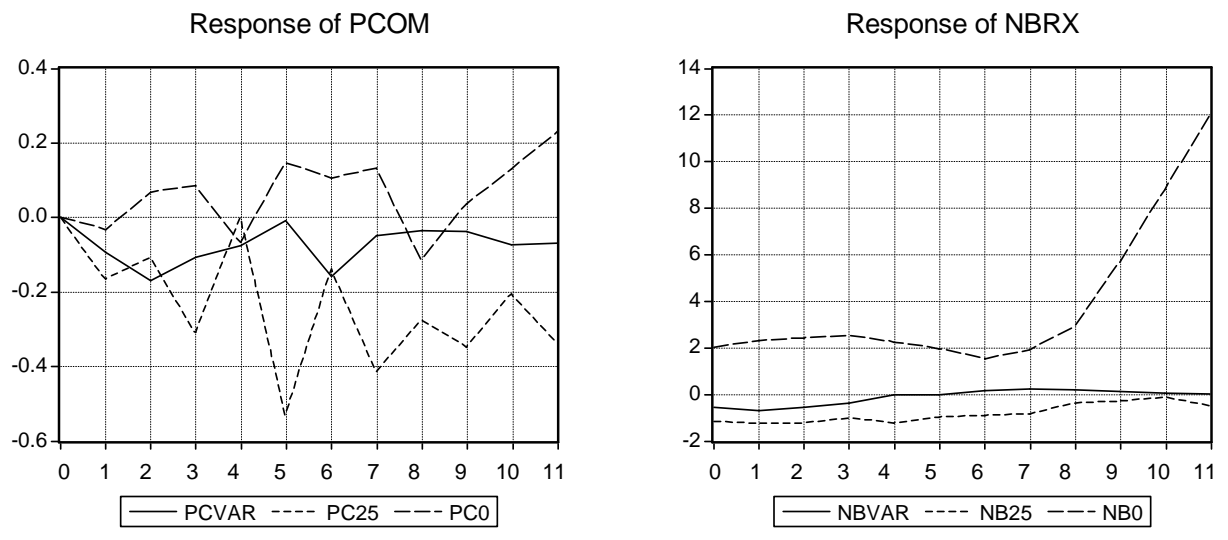

Response of M2

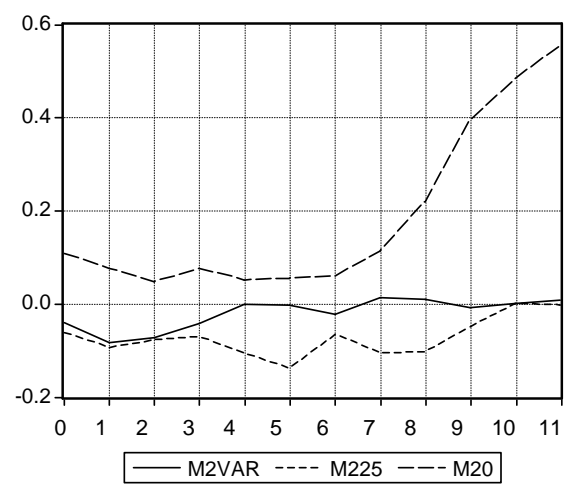

Notes:

- 12 Lag VAR as originally estimated in Evans and Marshall, 1998 (EV).

- Suffix "VAR" refers to the actual IRF from the EV paper.

- Suffix "25" refers to the IRF when the target shock is 0.25 .

- Suffix "0" refers to the IRF when the target shock is given by expectations. 


\section{Figure Captions}

Figure 1. Top panel: adjustment borrowing at the Fed discount window (dashed line) and the Fed Trading Desk's borrowing assumption (solid line). Middle panel: seasonal borrowing at the Fed discount window (dashed line) and the Fed Trading Desk's borrowing assumption (solid line). Bottom panel: the borrowing assumption minus seasonal borrowing.

Figure 2. Effect on $\mathbf{y}_{\tau+j}$ for $j=0,1, \ldots, 11$ of different definitions of an "innovation" in the Fed funds rate. Solid line: innovation means a forecast error in the VAR. Shortdashed line: innovation means that the Fed raised the Fed funds target. Long-dashed line: innovation means a forecast target change that failed to materialize. Different panels correspond to the different elements of $\mathbf{y}$. 